\title{
Health Protecting and Health Promoting Behaviors Among Preparatory School Students in Zagazig City
}

\author{
Eman Shokry Abd Allah ${ }^{1}$, Hanaa Hamdi Ali Elzeiny ${ }^{2}$, Ragaa Elsayed Abass Ali ${ }^{1}$ \\ ${ }^{1}$ Community Health Nursing, Faculty of Nursing, Zagazig University, Zagazig, Egypt \\ ${ }^{2}$ Psychiatric and Mental Health Nursing, Faculty of Nursing, Zagazig University, Zagazig, Egypt
}

Email address:

Emanshokry2012@yahoo.com (E. S. A. Allah)

\section{To cite this article:}

Eman Shokry Abd Allah, Hanaa Hamdi Ali Elzeiny, Ragaa Elsayed Abass Ali. Health Protecting and Health Promoting Behaviors Among Preparatory School Students in Zagazig City. American Journal of Nursing Science. Vol. 4, No. 5, 2015, pp. $247-254$.

doi: 10.11648/j.ajns.20150405.11

\begin{abstract}
Background. Adolescents' lifestyle change can be facilitated through a combination of learning experiences that enhance awareness, increase motivation, and build skills. The aim of this study was to describe the health protecting and health promoting behaviors among preparatory school students in Zagazig city. This study was aimed to identify the most common health-related modified and non-modified behaviors and how they effect on wellness of the preparatory school students. Research design: A descriptive cross-sectional design was used to carry out the study. Setting: in a preparatory school in Kafr Mohamed Gawish at Zagazig city on 150 male and female students aged 12 to 15 recruited through stratified cluster random sampling. Tools: The data were collected using an interview questionnaire. $\rightarrow$ (Please, give some info regarding questionnaire; it is self-structured? Validated? Self-administrative? How is it scoring? Additionally, how the behavior was assessed? (Cut-off $60 \%$ ). Tools: Two tools, the first tool (the data collection tool consisted of an interview questionnaire consisted two parts, socio-demographic characteristics, and medical history) and the second tool (a health promoting lifestyle questionnaire, in addition to a section asking students about the topics they suggest for personal growth. Results: The study results showed that approximately two thirds of adolescent preparatory school students from middle class families in rural areas had adequate total wellness behavior. The wellness behaviors' areas of most deficiency were those of exercise and mental activity, whereas the best areas were those of medication use, environmental, social, and spiritual aspects. Students' total wellness was significantly influenced by higher mother education, and lower crowding index, as well as the history of chronic diseases and previous surgery. Some of the wellness behavior aspects were also affected by students' age, gender, and father education. Conclusion and summary: Multivariate analysis identified $\rightarrow$ (Not in conclusion section) mother education as the only significant independent factor positively influencing adolescent's total wellness score. Students need to know more about topics related to nutrition, exercise, and anxiety. The wellness behaviors' areas of most deficiency are those of exercise and mental activity, whereas the best areas were those of medication use, environmental, social, and spiritual aspects. Recommendations: School health team should construct and implement special nutritional education intervention programs, promote physical exercise, and develop a hotline service for adolescents' health.
\end{abstract}

Keywords: Adolescence, School Health, Health Promotion, Health Protecting

\section{Introduction}

Adolescence is viewed as a transitional period between childhood and adulthood, whose cultural purpose is the preparation of children for adult roles (Steinberg and Albert, 2011). Adolescents are defined by the United Nations as those between the ages of 10 and 19; they constitute 1.2 billion in the world today (United Nations Children's Fund [UNICEF], 2012). Chronological age provides only a rough marker of adolescence, and scholars have found it difficult to agree upon a precise definition of adolescence (Cooney, 2010).

Health Promotion is the art and science of helping people discover the synergies between their core passions and optimal health, enhancing their motivation to strive for optimal health, and supporting them in changing their lifestyle to move toward a state of optimal health. Lifestyle change can be facilitated through a combination of learning experiences that enhance awareness, increase motivation, 
and build skills and, most important, through the creation of opportunities that open access to environments that make positive health practices the easiest choice (Ryan, 2011). Health promotion and associated efforts put into education, community development, policy, legislation and regulation are equally valid for prevention of communicable diseases, injury and violence, and mental problems, as they are for prevention of non-communicable diseases (World Health Organization [WHO], 2013).

A healthy lifestyle among adolescents and young adults leads to several psychosocial and behavioral protective factors as well as risk factors (Jessor et al., 2010). While risk factors raise the probability of involvement in risk behaviors, protective factors reduce the probability of involvement in risk behaviors by providing a model of positive social behaviors, by means of social and personal supervision and control, as well as a supportive social environment. Both risk and protective factors are present in all of our social and personal systems (Jessor et al., 2010). It is important to note that health behaviors are formulated throughout life with great emphasis on the earlier stages of life (Korn et al., 2013).

Community health nurses care for entire populations. By working with whole communities, they are able to educate people about health issues, improve community health and safety, and increase access to care. Community health nurses monitor health trends and identify health risk factors unique to specific communities; set local priorities for health-related interventions to provide the greatest benefit to the most people; advocate with local authorities to improve access to health services for underserved communities; design and implement health education campaigns and disease prevention activities, tell people about locally available health care programs and services to improve access to care; and provide direct health care services to vulnerable and at risk populations (Wolfe, 2012).

\subsection{Significance of the Study}

Over one third of the population in Egypt is currently between 10 and 19 years of age. They are experiencing puberty earlier, spending more years in school, and marrying later than previous generations. Moreover, health education is weak and the public school curriculum offers little to educate students about health in general and about reproductive health in particular. This represents a missed opportunity for the country, since the great majority of adolescents in Egypt are enrolled in school. Evidence from both developed and developing countries shows the importance of health programs in improving the overall health of young people and preparing them for their transition to adulthood.

\subsection{Aim of the Study}

The aim of this study is to describe the health protecting and health promoting behaviors among preparatory school students in Zagazig city.

NOTE: In case of proceeding to a further statistical analysis, it is recommended to change the Aim as follows:

This study was aimed to identify the most common healthrelated modified and non-modified behaviors and how they effect on wellness of the preparatory school students. Our secondary aim was to evaluate possible differences with respect to gender and demographic characteristics.

This study was aimed to identify the most common healthrelated modified and non-modified behaviors and how they effect on wellness of the preparatory school students

\section{Subjects and Methods}

Research design and setting: The study was conducted in a preparatory school in Kafr Mohamed Gawish at Zagazig city using a descriptive cross-sectional design.

Subjects: Sample criteria: All students enrolled in the identified school were eligible for inclusion in the study sample with the inclusion criterion of being 12 to 15 years old at the time of the study. No exclusion criteria were set. Sample size: The sample size was calculated to estimate the prevalence of a prevalence of health protective or health promotive behavior of $50 \%$ with a 3.5 standard error using the sample size equation for single proportion at $95 \%$ level of confidence, with population correction, and accounting for a non-response rate of about 5\% (EpiInfo 6.04 software package). Sampling technique: A stratified cluster random sampling technique was used in recruiting students in the sample. The strata were school grades and student gender, while the clusters consisted of classes.

\section{Tools for Data Collection}

Two tools were used:

Tool 1: The researcher prepared an interview questionnaire sheet to collect the data necessary to fulfill the study objectives. It comprised the following two tools: It was consisted of 2 parts:

Part I: The characteristics of the student such as age, sex, birth order, etc. as well as the parents' characteristics such as the educational level, occupation, income, $\rightarrow$ (As family income [annual] it is important in this study, please, give figures and definitions. how residence, family size, etc. This illustrated in table two and this Constance monthly

Part II: Medical history: This included questions regarding student's past and current health history, e.g. the history of chronic diseases as hypertension, diabetes mellitus, allergies, etc. It also involved questions about disabilities, previous hospitalization and or surgeries, as well as the smoking habit. There were also questions about family history of Cardiovascular cardiac $\rightarrow$ (, replace as Heart or Cardiovascular and witch particularly included) diseases, diabetes, and breast cancer. The last part included two questions about the feeling of depression and the perception of own body.

Tool 2: The health promoting lifestyle questionnaire adopted from Hettler (1982). The questionnaire is organized into two sections as follows: 
A. Wellness inventory: It focuses on the personal lifestyle and habits of the student as they affect health. It has 139 items on a 4-point Likert scale: never, rarely, often, and always. They are classified into four domains with 9 dimensions. The physical domain covers the dimensions of exercise, nutrition, self-care or personal hygiene, medication use, and environmental welfare. The emotional domain covers the emotional and intellectual or mental activity dimensions. The last two domains are the social and spiritual ones. The items are scored 0,1 , 2 and 3 for the responses never, rarely, often, and always, respectively. The scores are reversed for the negative statements. For each dimension and domain of factors, the scores of the items are summed-up and converted into a percent score. The respondent's behavior related to each domain/dimension or total was considered adequate in the percent score was $60 \%$ or higher and inadequate if less than $60 \%$.

B. Topics for personal growth: The last part of the tool asked participant to identify the areas in which they would like more information for continued learning assistance. It included 22 items.

Validation of the tools: During this phase, the researcher prepared the interview questionnaire form based on the reviewed literature. The wellness scale was translated into Arabic using the translate-back-translate method to preserve its validity (Behling and Law, 2000). Then, the prepared tool was tested for face and content validity by five experts in the field. These were from the Faculty of Nursing (|community health nursing and psychiatric nursing departments) and the Faculty of Medicine (community and psychiatric medicine departments). All recommended modifications were performed.

Pilot study: A pilot study was carried out on approximately $10 \%$ of the total sample to test the feasibility, clarity and applicability of the tools and to estimate the time needed to fill-in the sheets. Based on the pilot results, modifications were done in some phrases and words. Those who shared in the pilot study were not included in the main study sample.

The reliability of the wellness scale was assessed through calculating its Cronbach alpha coefficient. It turned to have an excellent reliability, internal consistency $\rightarrow$ (please, replace as $>$ internal consistency) with a coefficient 0.947 .

Fieldwork: The actual fieldwork started after an approval was obtained to conduct the study from the Director of preparatory school in Kafr Mohamed Gawish at Zagazig city to facilitate data collection. The researchers met with each student explaining the purpose and nature of the study and inviting to participate. The student who agreed to participate was then interviewed using the data collection form. Each student was interviewed individually for about 20-30 minutes. The researchers went to school three days weekly for data collection. About 5-6 students were interviewed each working day. The process of data collection was completed in a 6-month period, from the beginning of October 2012 to the end of March 2013.

Administrative analysis: An official permission was obtained from Zagazig Educational East Management and Principal of school.

Ethical considerations: The research protocol was approved by the research and ethics committee at the Faculty of Nursing, Zagazig University. The agreement for participation of the subjects was taken from parents through the school administration after full explanation of the aim of the study. Participants were given the opportunity to refuse the participation and/or to withdraw at any stage of filling the questionnaire. Also, they were reassured that their information would be confidential and used for research purpose only. Moreover, all the data collection forms were anonymous.

Statistical analysis: Data entry and statistical analysis were done using SPSS 16.0 statistical software package. Data were presented using descriptive statistics as frequencies and percentages for qualitative variables, and means and standard deviations and medians for quantitative variables. Spearman rank correlation was used for assessment of the inter-relations among numeric and ranked variables. In order to identify the independent predictors of the wellness score, multiple linear regression analysis was used after testing for normal distribution, linearity, and homoscedasticity, and analysis of variance for the full regression models were done. Statistical significance was set at $\mathrm{p}$-value $<0.05$.

\section{Results}

Table 1. Socio-demographic characteristics of students in the study sample $(n=150)$.

\begin{tabular}{l|l|l}
\hline Characteristics & Frequency & Percent \\
\hline School grade: & & 33.3 \\
1 & 50 & 33.3 \\
2 & 50 & 33.3 \\
3 & 50 & \\
Age (years): & & 58.0 \\
$<15$ & 87 & 42.0 \\
15 & 63 & \\
Range & $12.0-15.0$ & \\
Mean \pm SD & $14.1 \pm 0.9$ & 47.3 \\
Sex: & & 52.7 \\
Male & 71 & \\
Female & 79 & 39.3 \\
Birth order: & & 60.7 \\
1 & 59 & 2.0 \\
\hline 2+ & 91 & \\
Smoking & 3 & \\
\hline
\end{tabular}

Table 1 shows that the sample was equally distributed among the three school grades, with slightly more than half of the sample $(52.7 \%)$ being females. The age ranged between 12 and 15 years, with mean \pm SD 14.1 \pm 0.9 years. As for the birth order, about two-fifth of the students (39.3\%) were firstborn. Concerning students' smoking habits, only $3(2.0 \%)$ students were smoking. 
Table 2. Family characteristics of students in the study sample $(n=150)$.

\begin{tabular}{|c|c|c|}
\hline Family characteristics & Frequency & Percent \\
\hline Parents together: & 127 & 87.7 \\
\hline \multicolumn{3}{|l|}{ Father age (years): } \\
\hline$<45$ & 84 & 56.0 \\
\hline $45+$ & 66 & 44.0 \\
\hline Range & $32.0-64.0$ & \\
\hline Mean \pm SD & $44.0 \pm 5.7$ & \\
\hline \multicolumn{3}{|l|}{ Father education: } \\
\hline Illiterate & 11 & 7.3 \\
\hline Read/write & 31 & 20.7 \\
\hline Basic & 43 & 28.7 \\
\hline Intermediate & 31 & 20.7 \\
\hline University & 34 & 22.7 \\
\hline \multicolumn{3}{|l|}{ Father job: } \\
\hline Employee & 45 & 30.0 \\
\hline Manual worker & 105 & 70.0 \\
\hline \multicolumn{3}{|l|}{ Mother age (years): } \\
\hline$<40$ & 93 & 62.0 \\
\hline $40+$ & 57 & 38.0 \\
\hline Range & $25.0-54.0$ & \\
\hline Mean \pm SD & $38.3 \pm 5.6$ & \\
\hline \multicolumn{3}{|l|}{ Mother education: } \\
\hline Illiterate & 47 & 31.3 \\
\hline Read/write & 23 & 15.3 \\
\hline Basic & 21 & 14.0 \\
\hline Intermediate & 37 & 24.7 \\
\hline University & 22 & 14.7 \\
\hline \multicolumn{3}{|l|}{ Mother job: } \\
\hline Housewife & 132 & 88.0 \\
\hline Working & 18 & 12.0 \\
\hline \multicolumn{3}{|l|}{ Residence: } \\
\hline Urban & 1 & 0.7 \\
\hline Rural & 149 & 99.3 \\
\hline \multicolumn{3}{|l|}{ Crowding index: } \\
\hline$<2$ & 114 & 76.0 \\
\hline $2+$ & 36 & 24.0 \\
\hline \multicolumn{3}{|l|}{ Family income: } \\
\hline Saving & 73 & 48.7 \\
\hline Sufficient & 67 & 44.7 \\
\hline Insufficient & 10 & 6.7 \\
\hline
\end{tabular}

Table 3. Medical history of students in the study sample $(n=150)$.

\begin{tabular}{lll}
\hline Medical history & Frequency & Percent \\
\hline Have chronic disease (witch chronic disease & 43 & 28.7 \\
include??) Diabetes and hypertension & 4 & 2.7 \\
Have disability & 53 & 35.3 \\
Had previous surgery & 60 & 40.0 \\
Had previous hospitalization & 4 & 2.7 \\
Had previous pneumonia & 8 & 5.3 \\
Had rheumatic fever & 48 & 32.0 \\
Has chronic fatigue & 25 & 31.6 \\
Perform breast self-exam(girls) & & \\
Family history of: & 2 & 1.3 \\
Cardiac death <60 years & 31 & 20.7 \\
Diabetes & 19 & 12.7 \\
Breast cancer & & \\
Feel depressed: & 38 & 25.3 \\
Never & 76 & 50.7 \\
Sometimes & 36 & 24.0 \\
Often & & \\
Perception of own body: & 22 & 14.7 \\
Small & 106 & 70.7 \\
Average & 22 & 14.7 \\
Large &
\end{tabular}

Table 2 shows that the majority of the parents of students were living together $(87.7 \%)$. Among those not together, in about one-half $(47.8 \%)$ the cause was death. Fathers were mostly less than 45 years old $(56 \%)$, whereas mothers were mostly less than 40 years age (62\%). Regarding parent's education, the table indicates higher percentage of illiterate mothers (31.3\%) compared with fathers (7.3\%). Conversely, more fathers had a university degree $(22.7 \%)$ compared with mothers (14.7\%). As for job status, the majority of fathers $(70 \%)$ had manual work, while the majority of mothers $(88 \%)$ were housewives. All students except one (99.3\%) had rural residents. Slightly more than three-fourth of the students were living in homes with less than 2 persons per room as a crowding index. Slightly less than half of the students had sufficient income with saving (48.7\%). On the other hand, $6.7 \%$ had insufficient income.

As Table 3 describes, less than one-third of the students gave a history of chronic disease $(28.7 \%)$. The most common of these diseases were recurrent tonsillitis (12.7\%), and allergy (8.7\%). Meanwhile, $4(2.7 \%)$ of them had diabetes and $2(1.3 \%)$ had cancer. Four students were having a disability $(2.7 \%)$, mostly visual $3(75.0 \%)$. More than onethird of the students had previous surgery (35.3\%) and previous hospitalization (40\%). The table also shows that slightly less than one third of female students $(31.6 \%)$ were performing breast self exam. The family history was mostly positive for diabetes $(20.7 \%)$ and breast cancer $(12.7 \%)$. About half of the students $(50.7 \%)$ sometimes were feeling depressed, and one-fourth $(24.0 \%)$ felt this often. As for students' perception of their own body, the majority considered it average $(70.7 \%)$, while equal percentages felt it was either small or large.

Table 4. Total health behaviors as reported by students in the study sample $(n=150)$.

\begin{tabular}{llll|ll}
\hline Behaviors $\rightarrow \mathbf{~ ? ? ? ?}$ & \multicolumn{2}{l}{ Adequate $\left(\mathbf{6 0} \mathbf{\%}^{+}\right)$} & \multicolumn{3}{l}{ Scores $(\mathbf{m a x}=\mathbf{1 0 0})$} \\
\hline & No. & $\mathbf{\%}$ & Mean & SD & Median \\
\hline Exercise & 48 & 32.0 & 61.3 & 16.6 & 59.4 \\
Nutrition & 81 & 54.0 & 69.7 & 12.0 & 70.8 \\
Personal hygiene & 72 & 48.0 & 68.8 & 14.7 & 67.9 \\
Medication use & 110 & 73.3 & 77.7 & 17.0 & 83.3 \\
Environmental & 115 & 76.7 & 79.8 & 15.3 & 83.3 \\
Social & 112 & 74.7 & 78.6 & 15.1 & 82.5 \\
Emotional behavior & 98 & 65.3 & 73.4 & 12.8 & 76.0 \\
Mental activity & 62 & 41.3 & 66.4 & 14.6 & 67.9 \\
Spiritual & 112 & 74.7 & 78.7 & 16.4 & 82.5 \\
Total wellness: & & & & & \\
Adequate $(60 \%+)$ & 98 & 65.3 & 72.7 & 10.6 & 74.4 \\
Inadequate $\left(<60^{\circ}\right)$ & 52 & 34.7 & & & \\
\hline
\end{tabular}

Table 5. Health education topics requested by students in the study sample $(n=150)$.

\begin{tabular}{lll}
\hline Topics suggested & Frequency & Percent \\
\hline Nutrition & 108 & 72.0 \\
Exercise program & 82 & 54.7 \\
Anxiety associated with examination & 69 & 46.0 \\
Weight reduction & 57 & 38.0 \\
Mate selection & 56 & 37.3 \\
Time management & 55 & 36.7 \\
Automobile safety (use of helmet)? & 42 & 28.0 \\
Death ???? & 42 & 28.0 \\
\hline
\end{tabular}




\begin{tabular}{lll}
\hline Topics suggested & Frequency & Percent \\
\hline Smoking cessation & 39 & 26.0 \\
Over weight (BMI?) & 35 & 23.3 \\
Loneliness & 30 & 20.0 \\
Overcoming phobias & 30 & 20.0 \\
Breast self examination & 29 & 19.3 \\
Immunization & 29 & 19.3 \\
Spiritual values & 27 & 18.0 \\
Depression & 25 & 16.7 \\
Drug abuse & 19 & 12.7 \\
Relation/stress reduction & 17 & 11.3 \\
Enhancing relationships & 16 & 10.7 \\
Periodical breast examination & 15 & 10.0 \\
Suicidal thought ????? & 15 & 10.0 \\
Venereal diseases & 10 & 6.7 \\
Total number of topics & & \\
Range & $0-22$ & \\
Mean \pm SD & $5.6 \pm 3.5$ & \\
Median & 5 & \\
\hline
\end{tabular}

Yes , the content is correct

You are NOT obligated to present these topics as well NOT assessed using validated screening tools!!!

How could asking studnets about their sugegstions for health education tools be "assessed using validated screening tools"???III Is there a "validated screening tool" to ask for opinions and sugegstions???!!!

Other correection we can delete these seven topics if you refuse our rational.

Variables entered and excluded: age, gender, birth order, diseases, disabilities, parents' age, job, and father education, parental relations, crowding index, residence

What about mother job? As $88 \%$ are housewives! Is there any relation to wellness score?

Parents' age and job includes mother job. This means that mother job had no significant independent relation to wellness score.

Yes due to illiteracy of the majority of mother they cant good job and this affect the wellness

If it is possible - it would be also important to present the differences in Adequate and inadequate behaviors (each dimension) with respect to gender and the likelihood of reporting some of "bad" behaviors (Table 5) among students with poor wellness score $(<60 \%)$ using Odds Ratio with binary outcomes (logistic regression).

It is impossible because during our field work made total score of all dimensions.

1. This is not our aim

2. We already used linear regression analysis

Table 5 DOES NOT report "bad" behaviors but rather participants' suggestions for health education topics.

Table 4 summarizes students' total health behaviors. It shows that the highest scores were medication use, environmental, social, and spiritual. At the other end, the lowest scores were for exercise and mental activity. In total, slightly less than two-thirds of the students had adequate wellness behavior (65.3\%).

Concerning students' opinions regarding the health education topics they need, Table 5 shows that nutrition came highest and was mentioned by about three quarters $(72.0 \%)$ of them. It was followed by exercise $(54.7 \%)$ and anxiety associated with exams (46\%). On the other hand, venereal diseases came at the bottom of the list (6.7\%). The total number of topics suggested was 22 with a median 5 topics per student.

Table 6. Correlation between wellness domains scores and sociodemographic characteristics.

\begin{tabular}{lll}
\hline $\begin{array}{l}\text { Socio-demographic } \\
\text { characteristics }\end{array}$ & Wellness score & \\
\cline { 2 - 3 } Spearman rank correlation & p-value \\
\hline Grade & -0.0530 .053 & 0.5170 .517 \\
Age & -0.0220 .022 & 0.7920 .792 \\
Birth order & -.041 & 0.6170 .617 \\
Father age & .010 & Add 0.9040 .904 \\
Father education & Add 0.0930 .093 & .257 \\
Mother age & .086 & .296 \\
Mother education & $.269 * *$ & .001 \\
Crowding index & $-.180 *$ & .028 \\
Income & -.082 & .317 \\
\hline
\end{tabular}

(*) Statistically significant at $\mathrm{p}<0.05(* *)$ Statistically significant at $\mathrm{p}<0.01$

As regards the correlation between wellness total score and students' socio-demographic characteristics, Table 6 demonstrates that the only statistically significant correlations were with mother education $(\mathrm{r}=0.269)$ and crowding index $(\mathrm{r}=-0.180)$.

Table 7. Best fitting multiple linear regression model for wellness domains scores.

\begin{tabular}{|c|c|c|c|c|c|c|c|}
\hline & \multicolumn{2}{|c|}{ Unstandardized Coefficients } & \multirow{2}{*}{ Standardized Coefficients } & \multirow{2}{*}{ t-test } & \multirow{2}{*}{ p-value } & \multicolumn{2}{|c|}{ Confidence Interval (95\%) } \\
\hline & B & SE & & & & Lower & Upper \\
\hline Constant & 66.468 & 1.742 & & 38.152 & $<0.001$ & 63.025 & 69.911 \\
\hline Mother education & 2.175 & .556 & 0.3030 .303 & 3.912 & $<0.001$ & 1.076 & 3.274 \\
\hline
\end{tabular}

r-square $=0.12$

Model ANOVA: $\mathrm{F}=9.876, \mathrm{p}<0.001$

Table 7 presents that best fitting multiple linear regression model for total wellness score. It shows that mother education was the only statistically significant independent factor influencing this score after adjustment for the effects of age, gender, diseases, disabilities, parents' age, job and father education, parental relations, crowding index, and residence. It influence is positive and it explains $12 \%$ of the variation in wellness score indicated by the value of $r$-square.

\section{Discussion}

Adolescent health behaviors are among the factors that determine health status in adult life, so proper health behaviors should be established during this period of life (Wichman et al, 2008). Periodic national surveys and analysis of adolescents' health behaviors are thus essential in 
country's ongoing health promotion efforts (Center for Disease Control and Prevention [CDC], 2011). This is of particular importance in developing countries where about $70 \%$ of the young people live facing social, economic and health challenges greater than that of the industrialized countries (United Nations [UN], 2009).

The aim of the present study was to describe the health protecting and health promoting behaviors among preparatory school students in Zagazig city. The study included 150 preparatory school students where the age ranges between 12 and 15 years, with slightly higher percentage of females which could be attributed to their more compliance to school attendance compared with males who may skip school for work. The only significant gender differences in adolescents' health behaviors were related exercise and mental activity, which were higher among males compared with females. The findings are in agreement with Abdullwahab et al. (2011) in a study in Kuwait where males significantly exceeded females in the practice of physical activity. Similar findings were reported in South Africa (Micklesfield et al., 2014) and in Korea (Shin and Kang, 2014).

The current study revealed extremely low prevalence of smoking where only $3(2.0 \%)$ of them reported smoking. This rate is close to that reported by Tamim et al (2007) in a Lebanese study where the prevalence rate of cigarette smoking was $2.5 \%$. Our rate is very low compared to other local studies as Abdou (2004) in Zagazig where the prevalence was $13.8 \%$. Meanwhile, lower rates were reported in the United States among middle and high school youth, ranging between 3.5 and $6.7 \%$ (Centers for Disease Control and Prevention [CDC], 2013). The differences among studies might be influenced by under-reporting and denial due to fears from social pressures and norms.

The socio-demographic characteristics of the parents of the present study adolescents reveal a middle to low class category of a rural community with high prevalence of illiterate non-working mothers and of fathers with manual work. These characteristics are similar to those reported in similar studies in developing countries such as the study of Azadbakht (2011) in the city of Isfahan which reported high percentages of illiterate unemployed mothers and fathers with manual work. These characteristics might have negative influences on adolescents' health and behaviors. In fact, significant associations and correlations were revealed between adolescents' total wellness (health behavior) and mother education and crowding index. Most importantly, mother education was the only statistically significant independent factor influencing the total wellness score. Similar associations between parents' characteristics and adolescents health behaviors were previously reported (Hefler and Chapman, 2014; Lefkowitz et al, 2014).

As regards adolescents' physical health, the present study showed a high prevalence of chronic disease. The presence of chronic diseases showed significant associations with adolescents' health behaviors regarding nutrition, personal hygiene, and spiritual activity. This is anticipated given the experience of the affected adolescent with the chronic disease and the related instructions concerning nutrition and personal hygiene. Moreover, these adolescents may have more focus on spiritual aspects hoping that their conditions may improve. In congruence with this, Reynolds et al (2014) reported that among American adolescents having chronic diseases a positive spiritual coping may mitigate depression and maladaptive coping strategies among them.

A healthy practice assessed in the current study among female adolescents was that of Breast Self Examination (BSE). The study findings revealed that approximately onethird of these adolescents reported practicing it. The rate is higher than the rate reported in Turkey where $7.5-27.0 \%$ of university students performed BSE (Beydağ and Karaoğlan, 2007), and in another study which was as low as $6.7 \%$ (Tuna-Malak and Dicle, 2007). It is also higher than the rate of 26\% reported in Iran (Akhtari-Zavare et al, 2014).

According to the present study, more than three-fourth of the students reported practicing sports. However, a more detailed inquiry revealed that only about one-third of the sample practiced exercise properly in frequency and duration; in fact, this was the wellness area with the lowest score. The findings are in agreement with Guagliano et al. (2013) whose study in Australia revealed that the practice of organized sports alone among adolescent girls does not provide amounts of physical activity sufficient to meet daily recommendations.

As regards adolescents' behaviors related to nutrition, the results of the current study showed a lower level of adequacy compared with other behaviors. The most commonly reported bad dietary habits were those of high consumption of salt, tea, and coffee. This low adequacy might be explained by the generally low socio-economic level of the sample and the high percentage of illiterate mothers. Actually, a higher level of mother education was significantly related to better students' wellness behavior in nutrition. In agreement with this finding, Pekmezovic et al (2011) in a study in Belgrade and Serbia reported high percentages of students drinking coffee every day, and low percentages consuming fruits and vegetables. Similar findings were also mentioned by Abd El Aziz (2005) in a study on secondary school girls at Zagazig City.

The present study has also revealed generally good practices among adolescents regarding environment and medication use. This healthy behavior might be attributed to the fact that the incidence of diseases necessitating long-term use of medications in this phase of life is low. In agreement with this, Chi et al (2013), in a study in Taiwan reported that $<10 \%$ of the students reported that they would buy or obtain medication according to family or friends or traditional therapists' recommendations.

The present study revealed that the area of emotional health behavior was among the lowest of all dimensions. Although most adolescents reported pursuing positive mental activities such as realizing others points of view and exchanging ideas and notions with others, few of them reported exercising other important mental activities such as reading newspapers daily or magazines weekly. The lack of 
such important mental activities might be attributed to the family environment with high illiteracy and low socioeconomic standard, which may not encourage or afford such activities. Being significantly better among male adolescents reflects the relatively higher freedom to move and to be involved in activities compared with female adolescents. In congruence with this, Goldman (2012) stressed the importance of reading and acculturation for adolescents.

The social aspect of health behaviors was also assessed among adolescent students in the present study. The results showed that this aspect was among the highest areas assessed. The majority of the adolescents reported positive actions and attitudes such as having good feelings for others, realizing own ambitions well, and learning from faults. However, still some of them, although in low percentages, were not enjoying life, or were taking care of other's problems. The finding is in agreement with Doll et al (2004) who demonstrated that students in Greece had positive relationships, shared frequent enjoyable interactions with friends, and spent time together in unstructured classroom moments.

The spiritual health behavior of the adolescent students in the current study also showed high percentages of adequacy. The findings reflect the high tendencies to religiosity in our community, especially in rural areas. Meanwhile, the lack of seeking information is in congruence with their low tendencies to reading and seeking general information. In line with the present study, Susan et al (2005) in a study in the United States found that $89 \%$ of the adolescents reported a belief in God/Higher power and $77 \%$ stated that religion was important in their lives.

Overall approximately two-thirds of the current study students had adequate wellness behavior, indicating that still more than one-third of these adolescents need to improve. The results also showed significant associations of this behavior with mother education and crowding index, with the former being the only factor independently influencing adolescent's behavior. In agreement with this, Mireles-Rios and Romo (2014), in a study in California, underscored the important role on their adolescent daughters' wellness behavior.

The present study revealed a wide spectrum of topics of health education they needed. The most frequently mentioned topics were concerning nutrition exercise, and exams' anxiety. This is quite plausible since these topics reflect the most important daily life activities of these students, namely how to eat in a healthy manner, how to exercise properly, and how to prepare for school tests. These topics thus must take the highest priority in the health education activities delivered by school health. In this respect, AlBuhairan and Olsson (2014) in Saudi Arabia identified a gap between the training, knowledge and skills of health-care providers, and the needs to address health-care issues of adolescents, and emphasized the importance of building capacities to fill this gap. On the contrary, very low percentages of the current study adolescents expressed their needs to know about venereal diseases, suicidal thoughts, drug abuse, and breast self examination (for girls). The findings do not reflect a lack of need to know about these topics, but rather a reluctance and fear to mention them since these topics are considered as taboos in our community, and in particular in rural ones.

\section{Conclusion and Recommendations}

In conclusion, (Please, avoid repeating the results) about two thirds of adolescent preparatory school students from middle class families in rural areas have adequate total wellness behavior. The areas of most deficiency are those of exercise and mental activity. Mother education is the only significant independent factor positively influencing adolescent's total wellness score. Students need to know more about topics related to nutrition, exercise, and anxiety. The wellness behaviors' areas of most deficiency are those of exercise and mental activity, whereas the best areas were those of medication use, environmental, social, and spiritual aspects. Students' total wellness is significantly influenced by higher mother education, and lower crowding index, as well as the history of chronic diseases and previous surgery. Some of the wellness behavior aspects are also affected by students' age, gender, and father education

It is recommended that schools should implement health education and health promotion programs focusing on parents especially in mothers in order health education and health promotion programs focusing on parents especially in mothers in order to increase sound information, habits and values particularly in areas concerning nutrition, exercise, personal hygiene, environmental health, and mental activity, with guideline booklets and pamphlets. School health team should construct and implement special nutritional education intervention programs, promote physical exercise, and develop a hotline service for adolescents' health. Students with illiterate mothers may need special programs. Increasing public awareness through mass media and school health education programs is essential.

\section{References}

[1] Abd El -Aziz M. M. (2005): Assessment of nutritional status among secondary school girls in Zagazig City. Msc thesis. Faculty of Nursing. Zagazig University.

[2] Abdou M. N. (2004): Study of some adolescents problems among students in Sharkia Governrate. Unpublished Thesis Faculty of Medicine Zagazig University, pp.20 - 50.

[3] Abdullwahab N., Jennifer C., Ediriweera D., and Namal W. (2011): Department of Community Medicine and Behavioural Sciences, Faculty of Medicine, Kuwait University, P. O. Box 24923, 13110, Safat. Kuwait.Received 11 November 2010; Revised 27 December 2010; Accepted 27 February 2011.

[4] Akhtari-Zavare M., Ghanbari-Baghestan A., Latiff LA., Matinnia N., Hoseini M. (2014): Knowledge of breast cancer and breast self-examination practice among Iranian women in Hamedan, Iran. Asian Pac J Cancer Prev.;15(16):6531-4.

[5] AlBuhairan F. S., and Olsson T. M. (2014): Advancing adolescent health and health services in Saudi Arabia: exploring health-care providers' training, interest, and perceptions of the health-care needs of young people. Adv Med Educ Pract.;5:281-7. 
[6] Azadbakht L., Surkan P. J., Esmaillzadeh A., and Willett W. C. (2011): The Dietary approaches to stop hypertension eating plan affects C-reactive protein, coagulation abnormalities, and hepatic function tests among type 2 diabetic patients. J Nutr.;141: 1083-8.

[7] Behling O., and Law K. (2000): In: Translating questionnaires and other research instruments: Problems and Solutions. LewisBeck MS, editor. Thousand Oaks: Sage, pp. 1-70.

[8] Beydağ K. D. T., and Karaoğlan H. (2007): Effects of Training for Self-Breast Examination on Knowledge and Attitude of Nursing Students. Preventive Medicine Bulletin of Turkish Armed Forces 6:106-111.

[9] Centers for Disease Control and Prevention [CDC], (2011): Adolescent and school health. National initiative to improve adolescent health. Retrieved March 1, 2011, from http :// www.cdc.gov/heathyyouth/adolescenthealth /national initiative /index.htm.

[10] Centers for Disease Control and Prevention [CDC], (2013): Tobacco Product Use Among Middle and High School Students-United States, 2011 and 2012. Morbidity and Mortality Weekly Report;62(45):893-7.

[11] Chi H. Y. (2013): Evaluation of a health promoting school program to enhance correct medication use in Taiwan,Journal of food and Drug Analysis. http:// dx.doi.org /10.1016/j.jfda. 2013. 09. 013.

[12] Cooney E. (2010): "Puberty gap: Obesity splits boys, girls. Adolescent males at top of the BMI chart may be delayed". MSNBC. Retrieved 2010-05-22.

[13] Doll B., Zucker S., and Brehm K. (2004): Resilient classrooms: Creating health environments for learning. New York: Guilford Press.

[14] Goldman S. R. (2012): Adolescent literacy: learning and understanding content. Future Child.;22(2):89-116.

[15] Guagliano J. M., Rosenkranz R. R., and Kolt G. S. (2013): Girls' physical activity levels during organized sports in Australia. Med Sci Sports Exerc.;45(1):116-22.

[16] Hefler M., and Chapman S. (2014): Disadvantaged youth and smoking in mature tobacco control contexts: a systematic review and synthesis of qualitative research. Tob Control. pii: tobaccocontrol-2014-051756. doi: 10.1136/tobaccocontrol2014-051756. [Epub ahead of print]

[17] Jessor R., Mark S., Turbin., and Frances M.C.(2010): University of Colorado Predicting Developmental Change in Healthy Eating and Regular Exercise Among Adolescents in China and the United States: The Role of Psychosocial and Behavioral Protection and Risk.University of Colorado. Journal of Research on Adolescence; 1-19. Society for Research on Adolescence:DOI: 10.1111/j.15327795.2010.00656.x.

[18] Korn L., Gonen E., Shaked Y., and Golan M. (2013): Health perceptions, self and body image, physical activity and nutrition among undergraduate students in Israel. PLoS One.;8(3):e58543. doi: 10.1371/journal.pone. 0058543. Epub 2013 Mar 14

[19] Lefkowitz E. S., Kelly K. M., Vasilenko S.A., and Maggs J.L. (2014): Correlates of human papillomavirus vaccination among female university students. Women Health.; 54(6):487501
[20] Micklesfield L. K., Pedro T. M., Kahn K., Kinsman J., Pettifor J. M., Tollman S., and Norris S.A. (2014): Physical activity and sedentary behavior among adolescents in rural South Africa: levels, patterns and correlates. BMC Public Health.; 14:40

[21] Mireles-Rios R., and Romo L.F. (2014): Latina daughters' childbearing attitudes: the role of maternal expectations and education communication. Dev Psychol.;50(5):1553-63.

[22] Pekmezovic T., Popovic A., Tepavcevic D.K., Gazibara T., and Paunic M. (2011): Factors associated with health-related quality of life among Belgrade University students. Qual Life Res; 20:391-7.

[23] Reynolds N., Mrug S., Hensler M., Guion K., and MadanSwain A. (2014): Spiritual coping and adjustment in adolescents with chronic illness: a 2-year prospective study. J Pediatr Psychol.;39(5):542-51.

[24] Ryan M. (2011): Definition of Health Promotion: Definition of Health Promotion Health Promotion Advocates available at:healthpromotionadvocates.org /./definition-of-health-pr. on August 27, 2011

[25] Shin Y., and Kang S.J. (2014): Health behaviors and related demographic factors among Korean adolescents. Asian Nurs Res (Korean Soc Nurs Sci).;8(2):150-7.

[26] Steinberg L., and Albert D. (2011): "Judgment and Decision Making in Adolescence". Journal of Research on Adolescence; 21(1): 211-224.

[27] Susan G. (2005): Women Breast Cancer Foundation., Young women and breast cancer. [http:/ / cms.komen.org/ stellent/ groups/ public/ documents/ women document/ spbcyoung. pdf].

[28] Tamim H., Al-Sahab B., Akkary G., Ghanem M., Tamim N., El Roueiheb Z., Kanj M., Afifi R. (2007): Cigarette and nargileh smoking practices among school students in Beirut, Lebanon. Am J Health Behav.; 31(1):56-63.

[29] Tuna-Malak A., and Dicle A. (2007): Assessing the efficacy of a peer education model in teaching breast self-examination to university students. Asian Pac J Cancer Prev; 8:481-484.

[30] United Nations [UN], (2009): World Population Prospects: The 2008 Revision. CD-ROM Edition - Extended Dataset in Excel and ASCII formats.

[31] United Nations Children's Fund [UNICEF], (2012): The State of the World's Children, p. 133.

[32] Wichman M. E., Anderson N. L., and Greenberg C. S. (2008): The adolescent perception of invincibility and its influence on teen acceptance of the health promotion strategies. Journal of Pediatric Nursing; 23: 460 -468.

[33] Wolfe L.C. (2012): The profession of school nursing. In: Selectman School Nursing: A comprehensive Text. Philadelphia, FA Davis; 23(3):212-223.

[34] World Health Organization [WHO], (2013): Prevention of non-communicable Diseases (PND) and Mental Health, 20 Avenue Apia 1211 Geneva 27 Switzerland at the 8th Global Conference on Health Promotion 10 June 2013, available at : WHOhealthpromotion@who.int. 